\title{
Refusal to Autopsy: A Societal Practice in Pakistan Context
}

\section{Laila Akber Cassum}

Master of Science in Nursing (MScN) student, Aga Khan University, School of Nursing and Midwifry Karachi, Sind Pakistan

*Corresponding author: Laila Akber Akber Cassum, Master of Science in Nursing (MScN) student, Aga Khan University, School of Nursing and Midwifry Karachi, Sind Pakistan, Tel: 0334-3692741; Email: laila.akber.mn12@student.aku.edu

Rec date: May 30, 2014, Acc date: Oct 29, 2014, Pub date: Oct 31, 2014

Copyright: () 2014 Cassum LA. This is an open-access article distributed under the terms of the Creative Commons Attribution License, which permits unrestricted use, distribution, and reproduction in any medium, provided the original author and source are credited.

\begin{abstract}
Autopsies or post-mortem examinations have become a common practice in Western medicine for verifying the cause of death, and to obtain additional scientific information on certain diseases. In monotheistic religions autopsies present several ethical questions even though the advantages attributed to post-mortems in the West are well acknowledged by people living in this modern world. In Islamic Republic of Pakistan where Islam is the prevailing religion followed by the Muslims, Pakistani society have diverse perception, assumptions and hypothesis on the concept of autopsy. This presumption is due to presence of diverse objections raised in religious and sociocultural context. In our context, death ritual and practices are surrounded by religious and cultural beliefs and has a major influence on post mortem examination. Religious objections face a debate where the oppositions are in conflict with the laws. A definite and clear-cut answer is not possible based on Islamic beliefs nonetheless, for the advancement of medical science and betterment of humanity autopsies seems to be accepted.
\end{abstract}

Keywords: Autopsy; Post mortem examination; Religious and cultural perspectives; Pakistani context; Ethical principle

\section{Introduction}

I would like to begin my commentary paper with the words of Deepak Chopra [1], "If you obsess over whether you are making the right decision, you are basically assuming that the universe will reward you for one thing and punish you for another". Truly highlighted by him, decisions are a kind of hint to human brain, body and the environment to move in a certain direction. We all take multiple decisions in our routine life. However, some of the decisions involving life and health issues of a person such as marriage, divorce, deciding code status, removing life support gadgets, and disclosure of prognosis of terminal illnesses require deep analysis and deliberations before reaching to an ethical conclusion. In clinical framework, nurses are constantly involved in this process nevertheless; ethical decision making is not straightforward as lot of courage, honesty, ethical principles, and moral values have to be considered for side-lining their assumptions and prejudices to make a guilt free and neutral judgment in best interest of patient and families.

This paper is based on a true scenario of a 23 years old female, whose baby died in uterus just a week before her delivery date. It was neither umbilical cord around the neck, nor meconium aspiration or any other physical cause which could be identified. Besides, results of histopathological examination of placenta were unremarkable. It was difficult moment for her, and was in denial phase to face the truth of losing her baby. The medical team inquired her willingness for post mortem analysis to identify the cause. She was in state of shock and indecisive that whether to opt for autopsy or not? Finally, she refused for the analysis after mutual decision with her husband. Shortly after this incident, she conceived again and delivered successfully. On routine neonatal examination, the pediatrician identified murmurs on auscultation. They said if the murmurs will persist, then the neonate will have to go for further cardiac workup. This was a turning point in her life and was feeling guilty, that if she would have decided for the autopsy, perhaps the cause would have been identified and would not have resulted in cardiac issues in second child.

Several questions were echoing in my mind after reflecting upon the scenario. Should the mother refuse or opt for post mortem analysis? Should she be guilty that cardiac issues in neonate is the result of rejecting the option of autopsy? Why families in Pakistani context do not readily accept the notion of autopsy? What are some of the religious, legal and cultural perspectives attached to the notion of autopsy in Pakistani context? What is the perception of autopsy in Muslim world?

Indeed it was a challenging ethical issue and critical moment for the couple and particularly mother. Unexpected death of the loved one and especially if it is a child, leaves the parents in shock and grief which can cloud the decision making capacity. Oluwasola et al. [2] reports that in the last couple of decades, there is a decline in autopsy rate globally. Rathinam et al. [3] mentions that forensic or medicolegal and clinical or academic autopsies are the two major divisions. Oluwasola et al. [2] clarifies and adds on further that forensic autopsy is carried to rule out criminal cases where as clinical or academic autopsy is performed to evaluate medical reason in uncertain death. Generally, the decline is noticed in clinical autopsy rates more as compared to medico-legal. In Pakistani society, perhaps this notion is still surrounded by various myths, assumptions and misconceptions, and the subject is not well researched in identifying non-willingness and non-acceptance from family of deceased.

\section{My position and arguments}

After internalizing the picture, my standpoint is that the mother should have preferred for autopsy when she was given the option. The mother's decision favouring autopsy would not have been advantageous for her only in terms of identification of the cause of death, but also favourable for large number of people through advancement in medical knowledge and public health promotion. 
Genetics plays a significant role in many medical disorders, and autopsies provide pertinent information on inherited diseases which is valuable for family members to transform their life style and take future precautions.

Various ethical theories and principles are applicable in this scenario. Burkhardat and Nathaneil [4] have clearly highlighted utilitarianism school of thought and according to them, the true decision or course of action is the one which has the greatest benefit for maximum number of people. The main criterion of this virtue is based on utility that the action needs to be towards promoting greatest happiness for large number of people. A cross sectional study from rural Haryana where Rathinam et al. [3] reports that $86 \%$ of the respondents agreed that post mortem will assist in identifying the exact cause of death. In addition, Rathinam et al. [3] shares that timely detection of root cause of death assists the bereaved family to cope with the loss and accept the demise. Further, Sullivan and Paul [5], states that parental grief can be resolved through the process of autopsy in pediatrics. This finding is supporting my stance that if the mother would have consented for autopsy then the reason for death could have been easily uncovered. In addition, precautions in her prospective pregnancy might have prevented from development of cardiac issues in her second child. Sullivan and Paul [5] reveal the findings from their study that $77 \%$ and $64 \%$ of the pediatric parents were consoled that the autopsy results will add knowledge in medical field and will be beneficial for the people at large.

\section{Counter argument}

It is also difficult to escape from the fact of mother's decision which was not in the favour of autopsy examination. The mother's decision is justified as the first child means a lot to the parents and especially to the mother who made her fortunate and also completed the reason of being a woman. The nine months of gestation develops an everlasting bond of love and care but the unexpected loss made her suffer through immense pain, agony and psychological distress. My stance can be claimed on the grounds of ethical principles of autonomy, beneficence, non-maleficence as well as on religious and cultural context. Beauchamp and Childress [6] highlight the principle of autonomy, that an individual has a complete right and liberty to make independent decision on the matters which are affecting their lives. In the scenario, the decision taken by the parents not to opt for autopsy was unbiased as they are autonomous beings, and had freedom to take decisions, and therefore they did not want their innocent baby to go through pain, sufferings and disturb the peace of departed soul. Rathinam et al. [3] affirmed a finding from the study conducted in Haryana that, $77.3 \%$ of the relatives considered autopsy would disrupt the peace of deceased. The concept of beneficence and nonmaleficence are interrelated and highlighted in the scenario. Burkhardat and Nathaneil [4] emphasizes that beneficence is to do good and prevent harm while, non - maleficence stresses on purposefully avoiding those actions that can cause harm. Examining the scenario from the angle of beneficence and non-maleficence, the mother was not in favour of autopsy because she did not want to intentionally harm and mutilate the body of innocent soul just for the purpose of discovering the cause of death or for future precautions. In fact, her attempt of saving the baby from purposeful harm of autopsy was a kind of beneficial act and a symbol of love and care to the departed soul. In a study done by Rathinam et al. [3] $80 \%$ of the family members were anxious about the disfigurement and damage of the body due to autopsy. This outcome is consistent with the results of other studies carried out in Zambia and China by Lishimpi et al. [7] and Bierig [8]. Oluwasola et al. [2] mentions some of the other reasons of refusal, which are cost, pending funeral arrangements, and social stigma. A study conducted by Rathinam et al. [3] reports that $92.1 \%$ refused due to involvement of police and court, $83.4 \%$ favoured delay in funeral and $77.3 \%$ denied as autopsy will not bring their loved ones back.

\section{Argument}

My viewpoint is strongly advocated in the spheres of medical advantages and Sharia which favors obtaining medical help in health matters. Some of the benefits of autopsy includes discovery of inherited diseases useful in genetic planning for family members, validation of cause of death, invention of new medical remedies, presents justifications for injuries, accidents and murders, offers evidence for claiming insurance, and application of knowledge gained from autopsies for others to live longer and healthier life [9]. Burton and Collins [10] and Chaim [11] explains that from Islamic principle of Maslaha (Public benefit), beneficial method should be chosen always, when the benefits are greater than damage. Dada [12] writes that, the fatwa committee at Al-Azhar determined, that autopsy can be performed only when benefits outnumber harm such that infectious diseases can be restrained and students learn for community benefit. Makhluf fatwa consents for post mortem which is advantageous for medical science and deliver justice. Chaim [11] mentions that, Rasid Rida an Egyptian scholar was the first to discuss this issue and rationalized the examination of the deceased to authenticate death.

\section{Counter argument}

Some people might argue from religious and cultural perspectives. Several religions which currently exist have diverse religious and cultural traditions, customs, beliefs and practices attached to death ritual and autopsy. People from non-modernized world including Pakistan have deep-seated connections with religious and cultural beliefs and practices which revolve around death rituals and autopsy issues, and oppositions on religious foundations can be raised in both medico-legal as well as in clinical autopsies. Boglioli and Taff [13] and Davis and Peterson [14] both mentioned in their studies that, comparatively to clinical autopsies, autopsy of skeptical deaths can be opposed on religious basis and becomes a major obstacle in investigation procedure in medico legal situation. It is due to these inconsistencies between family autonomy and legitimacies the perception of autopsy among general public is enveloped by some assumptions and fallacies leading to refusal to autopsy.

\section{Religious aspect}

In most religions and cultures, autopsies are acceptable nevertheless; Islam does not provide concrete answer on this subject. Chaim [11] and Burton \& Collins [10] report the Islamic belief that, the deceased body is God's possessions and should be returned back to Him in the best condition. Based on this conviction, Islamic tradition does not encourage post-mortems analysis due to the presence of inflexible death rituals and customs such as burial of corpse within 24 hours, and not to be preserved etc. The Sharia supports to maintain the body in its original form and not to damage it by performing autopsy. Chaim [11] states about the scholar Abd al-Fattah that the dignity of the human body is lost when it loses its human form and considered a sin. Islam strongly supports the view point of the mother for denying the examination that the departed body might perceive pain. Sheikh [15] quotes the saying of Prophet Muhammad (P.B.U.H) 
Page 3 of 4

that, "to break the bone of a dead person is like breaking the bone of a living person". Chaim [11] concludes that a straight forward answer on this subject is not possible and standard legal sources do not speak on post mortem. Sheikh [15] reports that when there is no concrete answer in Quran and Hadith, Muslims generally considers Fatwa from renowned scholars and Ulemas who specialize in Fiqh as a legal and productive solution to the issues. He [15] further adds on that the subject was brought on the face of discussion autonomously in form of fatwas mostly after 20th century. Mohammed and Kharoshah [16] comments that based on the belief of "necessity permits the forbidden", the head of Islamic School of Jurisprudence in Egypt permitted autopsies in case of suspected deaths. Hence, on the foundations of pragmatic Islamic legal principle of Maslaha, autopsy is permissible and violation of deceased body is ignored for advancement of medical sciences and training of medical generation for public benefit. In addition, Davis and Peterson [14] states that in 1982, yet another legal committee in Egypt considered autopsy useful when the benefits outnumbered harm and if they can be well justified. Autopsies seem to be accepted for scientific researches, medical training, justifying cause of death or discovery of a new remedy. Though the subject is attached with some features unacceptable to Islamic law, however, the provided benefits are strong enough to supersede arguments of delay in burial and breach of integrity of body.

\section{Religious perception of autopsy in muslim world}

At present, autopsy is exercised in many countries including Islamic countries like Saudi Arabia, Egypt, Tunisia, and Qatar [16]. In many of the Arab countries where Islam is the prevailing religion, it is practiced in concurrence with the international scientific benchmarks [17]. Still, it is believed to be an unfavourable subject among the general population. This attitude is perhaps because of social concerns which are grounded on religious dogmas and principles. Generally, Department of Forensic Medicine practices the procedure of autopsy and is regulated under the Ministry of Health [16]. The authors [16] mentions that, the Kingdom of Saudi Arabia is completely governed on the basis of Islamic law derived from the teachings of Holy Quran and Hadith. Post Mortem Examinations are performed only if needed, and it can be even carried out without the consent of the family in doubtful cases. In Egypt, autopsies are practiced under clinical forensic medicine and the facts related to its practice are published in international journals which is a significant evidence of these examinations being followed in Muslim world $[18,19]$. In Tunisia and Qatar, it is practiced however; there are no statistics reporting the number and types of autopsies performed [20,21].

\section{Legal perspectives of autopsy in Pakistan}

The legal regulation in Pakistan has undergone through transformations in 1979 in order to bring uniformity with Islamic laws [22]. In criminal and suspected deaths, medico legal system in Pakistan examines the situation with the assistance of Police. Hadi [22] mentions that, nowadays in majority of the criminal cases medico legal examination or post mortem examination is a legitimate obligation to investigate the actual cause of death. Autopsies are performed by Medico Legal Officers (MLOs) in various hospitals at district and provincial levels.

\section{Why my position is more ethically sound?}

In the light of published literature and religious and legal perspectives, I consider my stance to be more ethically sound because in the tug of war of benefits and harm the ultimate benefit is to the field of science and humanity for good to prevail for other human beings. This altruistic act will have its own reward and blessings.

\section{Recommendations}

Due to emerging burden of diseases, the present day medicine is moving towards advancement and autopsy acts as a significant marker in providing scientific answers to the community. Some short and long term recommendations are crucial in form of awareness sessions through mass and electronic media. These are necessary to bring a change in people's perception and to replace the misconceptions with evidenced based and rationalized answers on this subject. The medical team should be trained in communication and counselling skills to obtain consent from the family. The physicians should be specially trained in forensic medicine and its certification so that substantial proof of death cannot be misjudged, neglected and contaminated [22]. The government should make efforts to train physicians in field of forensic medicine so that MLOs with forensic medicine expertise can serve the need of current time. In addition to the training of human resource, there is a dire need for the development of training institutes in the field of forensic medicine in the country [22]. Currently, King Edward Medical College under the university of Punjab and College of Physicians and Surgeons Pakistan is extending M. Phill and fellowship courses in forensic medicine [23]. Currently, a technique of "Virtopsy" or virtual autopsy is used in imaging radiology which is an innovative alternative to invasive nature of autopsy. It was first invented in Switzerland and currently used in UK and other countries [24]. All new inventions are attached with some advantages and disadvantages nevertheless, this technique has an advantage of non-invasive approach and tissue specimens can be drawn without dissecting the corpse. From many limitations of virtopsy, one of the major drawbacks is that it cannot appropriately identify the main cause of death [25]. Cultural objections are main barrier in our society. Religious and community stakeholders should be engaged to reduce the obstacles through public awareness educational programs, campaigns and panel discussions on the effectiveness and public health value of autopsies.

\section{Conclusion}

Pakistani society has a diverse perception, assumptions and hypothesis on the concept of autopsy. This presumption is due to presence of diverse objections raised in religious and sociocultural context. In our context, death ritual and practices are surrounded by religious and cultural beliefs and dogmas, and has a major influence on post mortem examination. Religious objections face a debate where the oppositions are in conflict with the laws. A definite and clear-cut answer is not possible based on Islamic beliefs nonetheless, for the advancement of medical science and betterment of humanity autopsies seems to be accepted and are performed in many western and Muslim countries including Pakistan.

\section{References}

1. Chopra D (2004) The book of secrets. Random House.

2. Oluwasola OA, Fawole OI, Otegbayo AJ, Ogun GO, Adebamowo CA, et al. (2009) The autopsy: knowledge, attitude, and perceptions of doctors and relatives of the deceased. Arch Pathol Lab Med 133: 78-82.

3. Rathinam RD, Chopra M, Singh A, Bhardwaj A, Prasanna M et al. (2013) Perceptions of relatives towards medico - legal investigation and forensic 
Citation: Cassum LA (2014) Refusal to Autopsy: A Societal Practice in Pakistan Context. J Clinic Res Bioeth 5: 198. doi:

autopsy: A Cross sectional survey from rural Haryana. Journal of Medical Society 27: 173-176.

4. Burkhardt M, Nathaniel A (2001) Ethics \& Issues in Contemporary Nursing (2nd Edn), Australia: Delmar.

5. Sullivan J, Monagle P (2011) Bereaved parents' perceptions of the autopsy examination of their child. Pediatrics 127: e1013-1020.

6. Beauchamp T, Childress J (2001) Principles of Biomedical Ethics (5th Edn), New York.

7. Lishimpi K, Chintu C, Lucas S, Mudenda V, Kaluwaji J, et al. (2001) Necropsies in African children: consent dilemmas for parents and guardians. Arch Dis Child 84: 463-467.

8. $\quad$ Bierig JR (2001) Informed consent in the practice of pathology. Arch Pathol Lab Med 125: 1425-1429.

9. (2001) Autopsy: Aiding the living by understanding death. College of American Pathologist.

10. Burton EC, Collins KA (2012) Religion and Autopsy.

11. Rispler-Chaim V (1993) The ethics of postmortem examinations in contemporary Islam. J Med Ethics 19: 164-168.

12. Dada MA (1998) Islam and Autopsy.

13. Boglioli LR, Taff ML (1990) Religious objection to autopsy. An ethical dilemma for medical examiners. Am J Forensic Med Pathol 11: 1-8.

14. Davis GJ, Peterson BR (1996) Dilemmas and solutions for the pathologist and clinician encountering religious views of the autopsy. South Med J 89: 1041-1044.

15. Sheikh A (1998) Death and dying--a Muslim perspective. J R Soc Med 91: 138-140.
16. Mohammed M, Kharoshah MA (2014) Autopsy in Islam and current practice in Arab Muslim countries. J Forensic Leg Med 23: 80-83.

17. Al Madani OM, Kharoshah MA, Zaki MK, Galeb SS, Al Moghannam SA, et al. (2012) Origin and development of forensic medicine in the Kingdom of Saudi Arabia. Am J Forensic Med Pathol 33: 147-151.

18. Kharoshah MA, Zaki MK, Galeb SS, Moulana AA, Elsebaay EA (2011) Origin and development of forensic medicine in Egypt. J Forensic Leg Med 18: 10-13.

19. Gad ElHak SA, El-Ghazali AM, Salama MM, Aboelyazeed AY (2009) Fatal suicide cases in Port Said city, Egypt. J Forensic Leg Med 16: 266-268.

20. Mghirbi T, Aissaoui A, Turki E, Chadly A (2004) Forensic medicine in Tunisia. Forensic Sci Int 146 Suppl: S33-35.

21. Bhootra BL (2006) Forensic pathology services and autopsy law in state of Qatar. J Clin Forensic Med 13: 15e20.

22. Hadi S (2003) Medicolegal impact of the new hurt laws in Pakistan. J Clin Forensic Med 10: 179-183.

23. (1999) Proceeding of the 38th Meeting of College of Physicians and Surgeons of Pakistan.

24. Thali MJ, Jackowski C, Oesterhelweg L, Ross SG, Dirnhofer R (2007) VIRTOPSY - the Swiss virtual autopsy approach. Leg Med (Tokyo) 9: 100-104.

25. Underwood J (2012) Post-mortem imaging and autopsy: rivals or allies? The Lancet. 379: 100e2. 